\title{
A INVISIBILIDADE NA FRONTEIRA: UMA ANÁLISE SOBRE A "FAIXA LIVRE" LOCALIZADA ENTRE SETE QUEDAS - BR E PINDOTY PORÃ - PY
}

\author{
Invisibility at the frontier: an analysis of the "Faixa Livre" between \\ Sete Quedas -BR and Pindoty Porã - PY
}
La invisibilidad en la frontera: un análisis sobre la "Faixa Livre" ubicada entre Sete Quedas - BR y Pindoty Porã - PY

\begin{abstract}
Leonardo Calixto Maruchi ${ }^{*}$
Lidiane Cristina Lopes Garcia de Souza**

*Universidade Federal da Grande Dourados (UFGD) - leomaruchi06@hotmail.com **Universidade Federal da Grande Dourados (UFGD) - lidcris_@hotmail.com
\end{abstract}

Recebido em 31/01/2020. Aceito para publicação em 17/03/2020

Versão online publicada em 05/05/2020 (http://seer.ufrgs.br/paraonde)

Resumo:

Este artigo é fruto de um trabalho de campo realizado pela turma de mestrandos e doutorandos do Programa de Pós Graduação em Geografia da Universidade Federal da Grande Dourados (UFGD), durante a disciplina "Tópicos Especiais em Geografia" ministrada pelo Prof. Dr. Jones Dari Goettert. Nesta aula de campo, foram realizadas entrevistas com moradores da chamada "faixa livre", que é uma zona neutra na fronteira entre Brasil e Paraguai no sul do estado do Mato Grosso do Sul. A particularidade desse lugar e das pessoas que ali vivem mostra como a fronteira é um lugar em que as relações se dão de maneira única, e que apesar de ser um lugar contraditório e com diversos problemas, também é um lugar de multiplicidades, saberes e vivências únicas.

Palavras-chave: Fronteira. Faixa livre. Multiplicidade.

\begin{abstract}
:
This article is the result of a field work carried out by the group of masters' and doctoral students of the Postgraduate Program in Geography of the Federal University of Grande Dourados (UFGD), during the discipline "Special Topics in Geography" taught by Prof. Dr. Jones Dari Goettert. In this field lesson, interviews were conducted with residents of the so-called "faixa livre" (a Brazilian Portuguese concept that can be translated to English as "free range"), which is a neutral zone on the border between Brazil and Paraguay in the southern state of Mato Grosso do Sul. The particularity of this place and the people living there shows how the border is a place where relations occur in a unique way, and despite being a contradictory place and with various problems, it is also a place of unique multiplicities, knowledge and experiences.
\end{abstract}

Key words: Border. Free Range. Multiplicity.

\section{Resumen:}

Este artículo es fruto de un trabajo de campo realizado por la clase de estudiantes de maestría y doctorado del Programa de Post Graduación en Geografía de la Universidad Federal de la Grande Dourados (UFGD), durante la disciplina "Temas especiales en Geografía" impartida por el Prof. Dr. Jones Dari Goettert. En esta clase de campo, se realizaron entrevistas con residentes de la 


\begin{abstract}
llamada "faixa livre" (concepto de la lengua portuguesa que se puede traducir como "franja libre"), que es una zona neutra en la frontera entre Brasil y Paraguay en el sur del estado de Mato Grosso do Sul. La particularidad de ese lugar y de las personas que allí viven muestra como la frontera es un lugar en que las relaciones se dan de manera única, y que a pesar de ser un lugar contradictorio y con diversos problemas, también es un lugar de multiplicidades, saberes y vivencias únicas.
\end{abstract}

Palabras clave: Frontera. Franja libre. Multiplicidad.

\title{
1. Introdução
}

Durante o primeiro semestre do ano de 2018 o Programa de Pós Graduação em Geografia da Universidade Federal da Grande Dourados (UFGD) ofertou a disciplina "Tópicos Especiais em Geografia", ministrada pelo Prof. Dr. Jones Dari Goettert, durante a disciplina, um dos diversos temas debatidos foi a "fronteira", e, portanto, uma aula de campo na região de fronteira se mostrou uma alternativa muito importante para a ampliação do conhecimento e da discussão em torno deste tema.

Entendemos que a proximidade com a linha internacional e o contato próximo com a fronteira seca com outro país uma particularidade interessantíssima de nossa região, que fica no sul do estado de Mato Grosso do Sul (MS). Essa particularidade desperta curiosidades de citadinos de outras regiões não habituados a proximidade com uma linha internacional de fronteira.

Iniciamos uma revisão dos referenciais teóricos com a finalidade de refletir a partir da perspectiva da fronteira, a partir daí um viés norteador que passou a ser muito discutido foi o ponto de vista dos sujeitos sociais em relação à fronteira, entendemos que deveríamos buscar de alguma forma dar ênfase ao cotidiano dos moradores próximos à linha internacional e das lideranças políticas locais para tentarmos compreender as identidades/ multiplicidades que fazem parte daquele lugar. Pois, a fronteira é imaginada como lócus do conflito e do (des)encontro, dos estereótipos a serem destruídos através das vivências e experiências.

Além da preocupação metodológica, o compromisso político de denúncia das injustiças é um dos traços fundamentais de diversos autores da Geografia, que nos inspiram ao vivenciar por algumas horas realidades como as que serão retratadas/sentidas a seguir, o sentimento de justiça floresce e torna-se angústia.

Concordando com Raffestin (2005, p.10), atualmente, devido especialmente aos fenômenos da integração, desenvolveu-se um mito das fronteiras nacionais sucedido pelo mito da eliminação das fronteiras nacionais. Além de uma ameaça as vidas que ali (sobre)vivem, é uma preocupação relevante para aqueles que zelam pelos ensinamentos que a faixa fronteiriça nos proporciona.

A partir dessa perspectiva, levando em consideração a compreensão da ciência geográfica, é possível que seja uma forma de deduzir o papel de cada fronteira material e/ou simbólica, analisando uma realidade específica e sob o

ParaOnde!?, Porto Alegre, v.13, n.2, p.152-164, 2020.http://seer.ufrgs.br/paraonde Edição Especial - VII Seminário Internacional de Estudos Fronteriços 
ponto de vista do entendimento de cada um, o que possibilita o fortalecimento de várias abordagens de variadas formulações.

De maneira geral, esta pesquisa teve como objetivo entender e denunciar as diversas contradições e problemas que são característicos da região de fronteira, buscando mostrar que o Estado não consegue dar suporte para diversas pessoas simplesmente por estarem vivendo em um lugar que o próprio Estado decidiu como um "lugar de ninguém". Mas além de entender e denunciar estes problemas, esta pesquisa busca também de alguma forma mostrar as riquezas culturais que uma região de fronteira pode proporcionar.

Após a discussão de diversos autores a respeito do tema, os mestrandos e doutorandos juntamente ao professor Jones ficaram do dia 12 ao dia 14 de julho de 2018 conhecendo e estudando a cidade de Sete Quedas MS. A cidade fica localizada no extremo sul do estado de Mato Grosso do Sul, a pequena cidade que em 2010 tinha cerca de 10.780 habitantes (segundo estimativa do Instituto Brasileiro de Geografia e Estatística - IBGE de 2010) faz fronteira com Pindoty Porã, uma pequena cidade do Paraguai. Localizada no departamento de Canindeyú

A metodologia principal utilizada neste trabalho foi a de pesquisa qualitativa através de entrevistas' com a população local e seus representantes. A imagem (Figura 1) a seguir é um mapa aéreo da cidade de Sete Quedas e Pindoty Porã (destacada), os outros pontos em destaque (Conjunto Habitacional Iporã e a "faixa livre".) são alguns dos locais visitados durante a aula de campo. Nestes locais foram realizadas entrevistas com alguns moradores na tentativa de entender as relações e vivências que constituem e marcam aquele lugar. Vale destacar também que foi feita uma conversa com representantes da prefeitura local de Sete Quedas, as experiências e conversas obtidas nesses diferentes locais e diferentes sujeitos possibilitou entender um pouco mais como a região de fronteira é um lugar cheio de contradições e problemas, mas também um lugar com experiências e vivências únicas que apenas os moradores locais conseguem sentir e viver, e talvez por isso gostem tanto daquele lugar.

ParaOnde!?, Porto Alegre, v.13, n.2, p.152-164, 2020.http://seer.ufrgs.br/paraonde Edição Especial - VII Seminário Internacional de Estudos Fronteriços 


\section{Figura 1 - Municípios de Sete Quedas (BR) e Pindoty Porã (PY).}

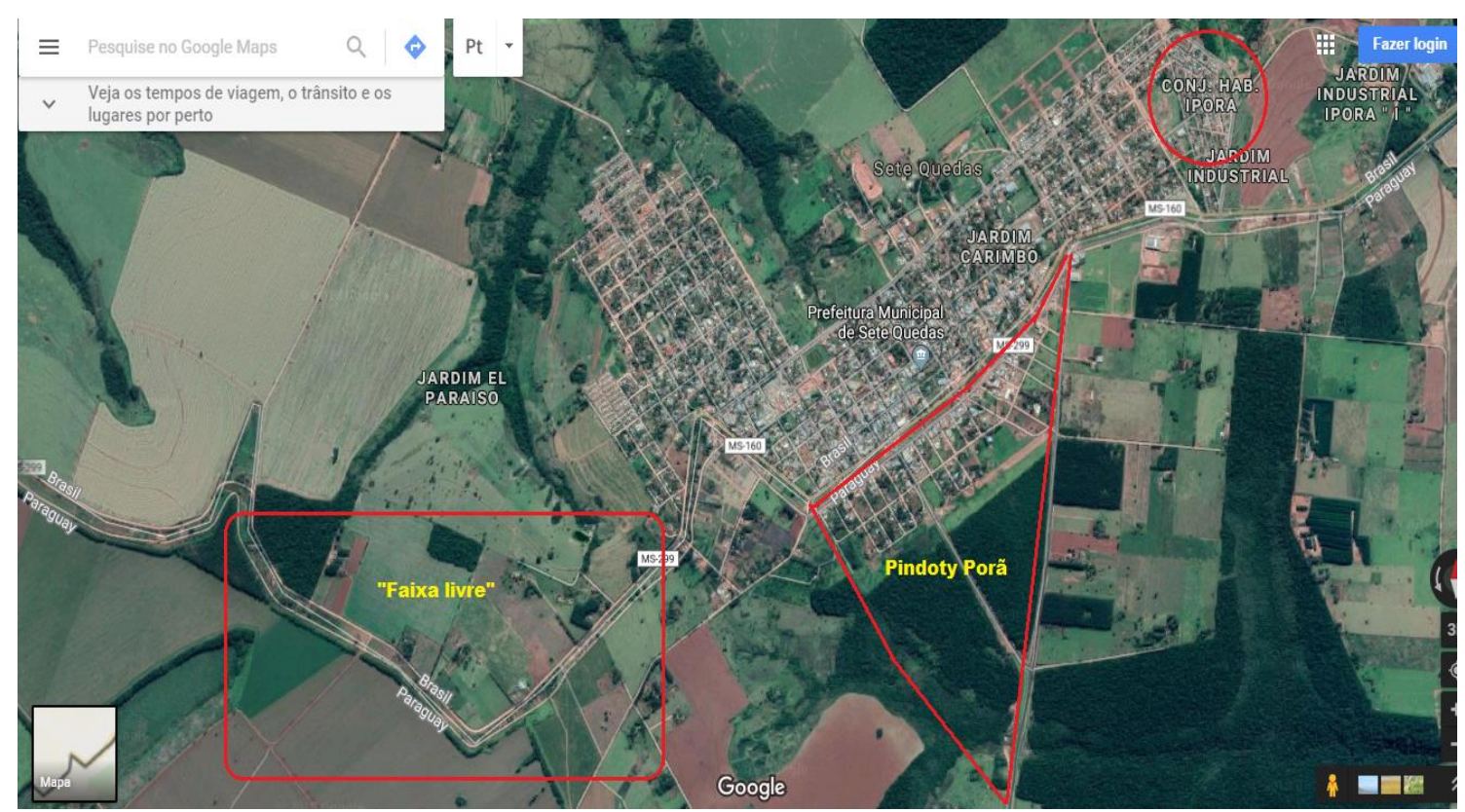

Fonte: Google Maps. Acesso em julho de 2018 Org.: MARUCHI (2018).

Apesar de serem países diferentes, basta aos moradores de ambos os países atravessarem uma rua que já estão tecnicamente em outro território, com leis, tradições e línguas diferentes. Devido à proximidade entre estes municípios e principalmente com o país vizinho (Paraguai), os padrões que orientam a vivência são resultados da influência e mistura de culturas, conflitos, processos e particularidades diplomáticas que espelham sua condição geográfica (OLIVEIRA, 2005, p. 33).

\section{Desenvolvimento}

A foto abaixo (Fotografia 1) é do marco internacional localizado no centro do que os moradores locais chamam de "faixa livre", que tecnicamente, é uma linha imaginária de alguns metros de largura que divide o Brasil e o Paraguai, ou seja, a "faixa livre" é uma zona neutra de transição entre os territórios brasileiro e paraguaio. Portanto, ambos os países definiram que a faixa livre deveria der um local sem moradores de ambos os países, já que não pertence a nenhum deles, e, portanto, políticas de estado nestes locais não existem, mas como podemos ver na imagem, existem várias casas, barracas e até mesmo estabelecimentos localizados dentro dela. 


\section{Fotografia 1 - Marco internacional localizado na "faixa livre" entre Sete Quedas (BR) e Pindoty Porã (PY).}

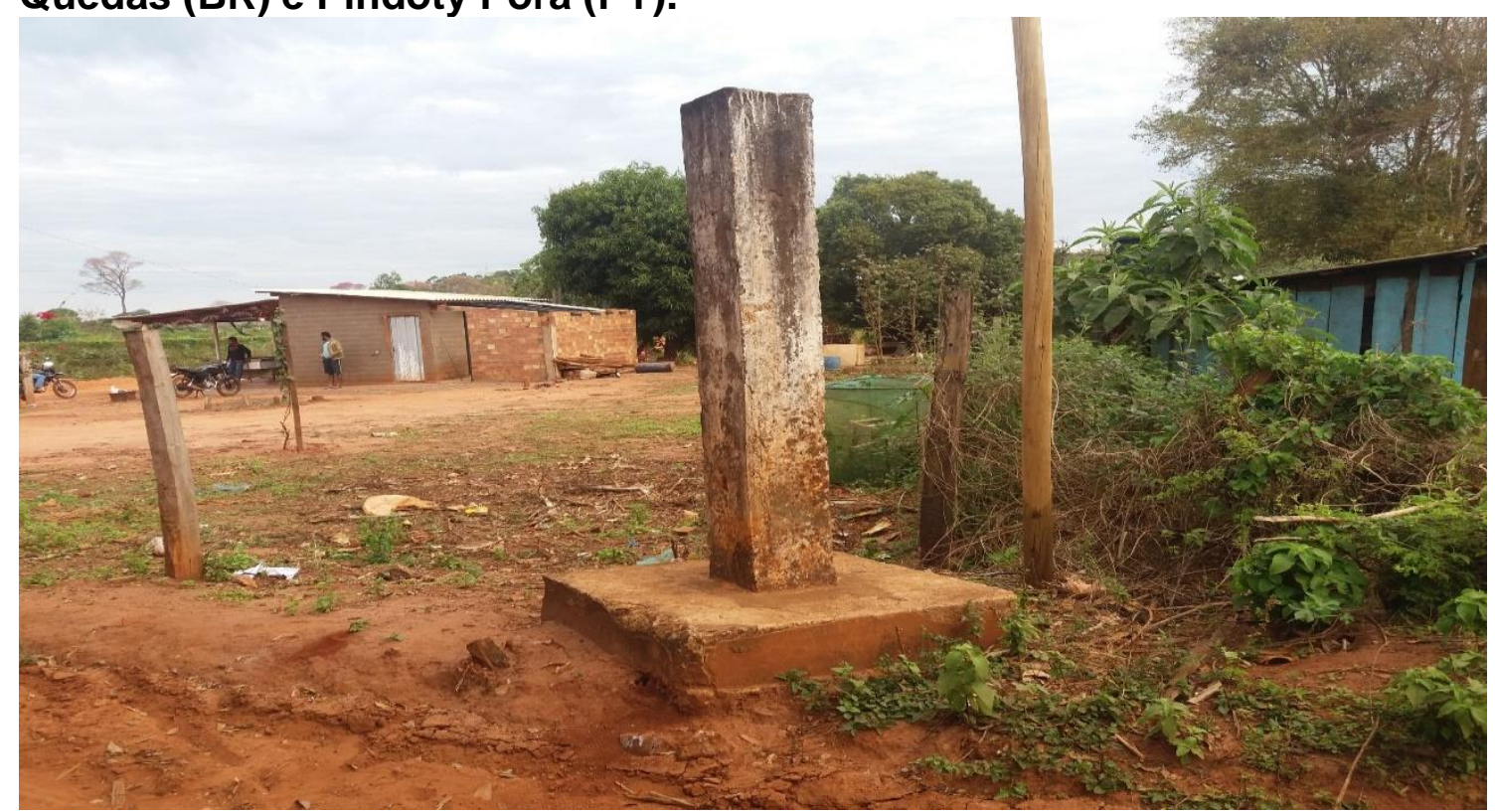

Fonte: MARUCHI (2018)i

A primeira troca de experiência foi com Fernando, ser humano, único e múltiploiii, citadino a trinta anos do município (desde o período em que Sete Quedas fazia parte do município de Iguatemi), morador há treze anos no bairro de El Paraiso, do "lado" brasileiro da linha internacional, a casa de Fernando fica a poucos metros da "faixa livre".

Segundo Fernando (MARUCHI; SOUZA, 2018 A), sua propriedade (Fotografia 2) é um conjunto de lotes devidamente quitados e que denomina como chácara, devido ao cultivo de algumas culturas como milho, mandioca e algumas ervas para chá e usos medicinais como a moringa, que é um tipo de remédio natural com vários benefícios como controle de pressão alta, também podemos considerar que para o Fernando a moringa é uma "geografia portátil" (MARQUEZ, 2009, p. 6).

Chefe de família e técnico em automatização, Fernando ganha a vida instalando portões eletrônicos, tanto no Brasil, onde além do município que reside, atende Paranhos e Tacuru, e também no Paraguai, no município de Pindoty Porã. Fernando e um exemplo da intensa relação existente entre os dois países que se interferem e criam uma relação de interdependência econômica e social. 


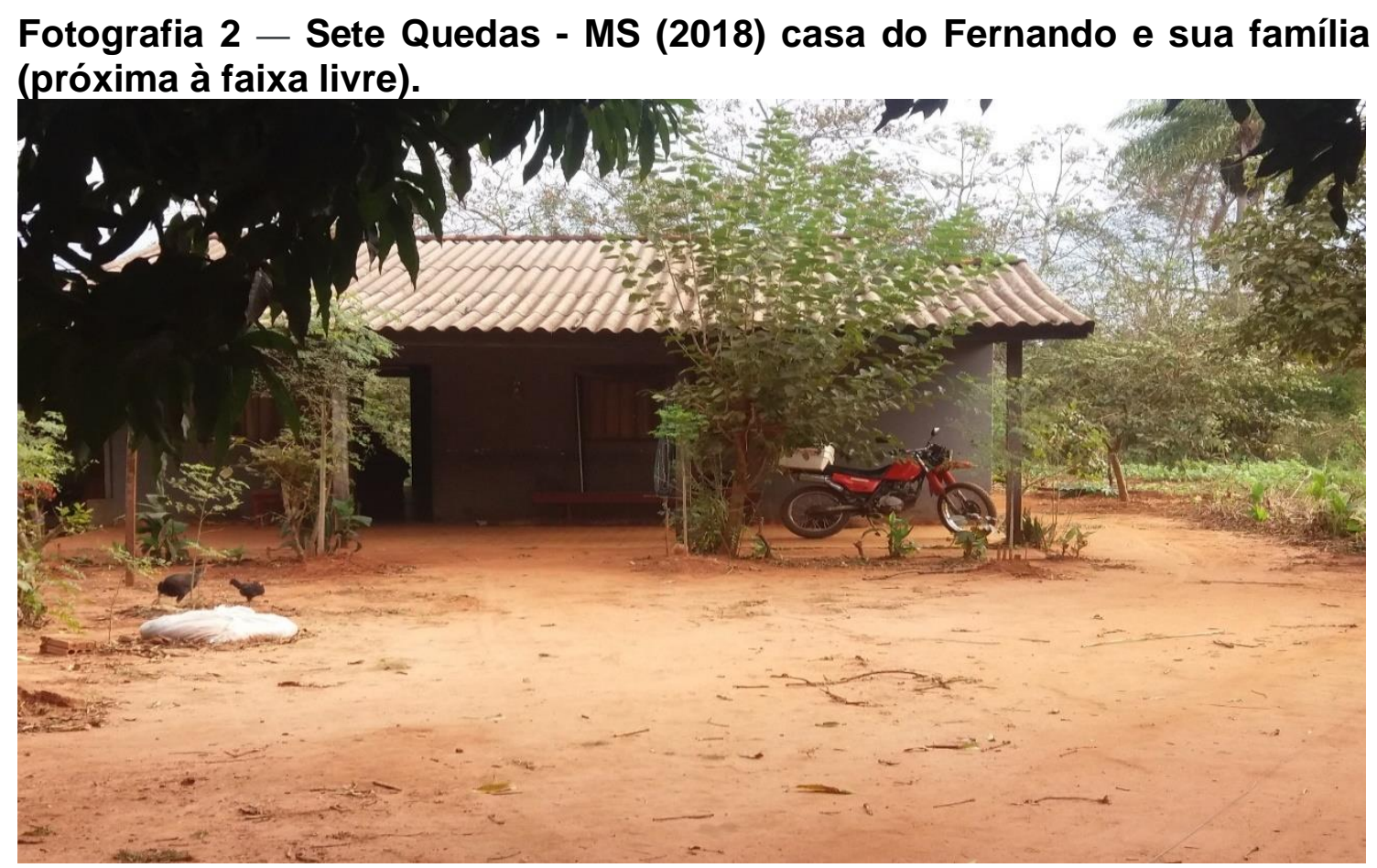

Fonte: MARUCHI (2018).

Como já mencionado, a falta de reflexão autoriza confusões sobre a compressão de fronteira, neste caso, em referência aos limites e (des)encontros entre cidades de países distintos, uma vez que, a palavra fronteira possui mais de um significado na práxis. A representação de fronteira que a cultura de outras regiões que não vivem tal realidade dissemina é vaga, é preocupante e preconceituosa, pois é a negação de toda uma história (RAFFESTIN, 2005, p.10).

A história que se nega e não é devidamente contada, vai além de perspectiva temporal, é preciso considerar a história que está penetrada nos rituais, nas falas, nos olhares, nas ações, promovendo uma série de danos à riqueza e as diferenças que a fronteira carrega consigo, apesar disso, mesmo quando tentam apaga-la a fronteira resiste e sobrevive.

A intensidade das relações sociais fronteiriças está diretamente ligada à porosidade, à densidade e mistura demográfica, ao cotidiano, ao conflito, as trocas culturais e as permutas mercantis proporcionadas pela proximidade com - país vizinho, pois quanto mais próximos, mais complexas serão as ferramentas socioespaciais a serem consideradas e compreendidas. [...] "A fronteira é um espaço de rebeldias. Foi assim e continuará assim. Mas toda fronteira é rebelde? Sim. Todavia, há que se localizar a intensidade dessa rebeldia e como ela na fronteira se estabelece" (OLIVEIRA, 2015, p.123).

Fernando também falou um pouco sobre as dificuldades enfrentadas pelos seus vizinhos que moram na faixa, ele afirma que como essas pessoas não possuem casas dentro do território brasileiro ou paraguaio as casas não possuem endereço, e, portanto ele empresta a sua casa para servir de

ParaOnde!?, Porto Alegre, v.13, n.2, p.152-164, 2020.http://seer.ufrgs.br/paraonde Edição Especial - VII Seminário Internacional de Estudos Fronteriços 
endereço para que os moradores da faixa possam ter alguma localidade para poderem preencher documentos e receberem entregas. Com relação a essa problemática, Fernando sob olhar de pertencimento ao lugar há treze anos, se expressa:

A faixa não tem endereço, está entre o Brasil e Paraguai, a gente chama de faixa livre. A relação aqui é tranquila, pessoal é muito gente boa, ali mesmo tem o boteco na faixa e é tranquilo pra caramba. Às vezes acontece, todo lugar tem. (MARUCHI; SOUZA, $2018 \mathrm{~A}$ ).

A fala de Fernando mostra que as impressões e as vivências da população local muitas vezes mostram uma realidade diferente dos estereótipos comuns que pessoas que não vivem naquele lugar reproduzem. $A$ sensação de segurança é algo muito relativo nesta região, uma vez que a fala de Fernando demonstra uma "outra realidade", diferente daquele senso comum reproduzido por grande parte da população de Sete Quedas que classifica o local como sendo um lugar muito perigoso, sendo associado a um lugar de atividades consideradas "ilegais".

Além disso, torna-se necessário ressaltar que, a "faixa livre" vive sob a ausência de políticas públicas, as pessoas que vivem naquele lugar na maioria das vezes foram obrigadas a viverem lá por não conseguirem se estabelecer em outros locais. É evidente a grande dificuldade que as pessoas deste local enfrentam devido ao baixo poder aquisitivo que possuem (Fotografia 3) e também ao Estado que negou ações que consequentemente negligenciam a produção social nessa faixa. Mas mesmo enfrentando muitas dificuldades, as falas dos sujeitos que vivem neste lugar demonstram ter um afeto e um sentimento de pertencimento muito forte com o lugar.

\section{Fotografia 3 - Moradia simples localizada na "faixa livre".}

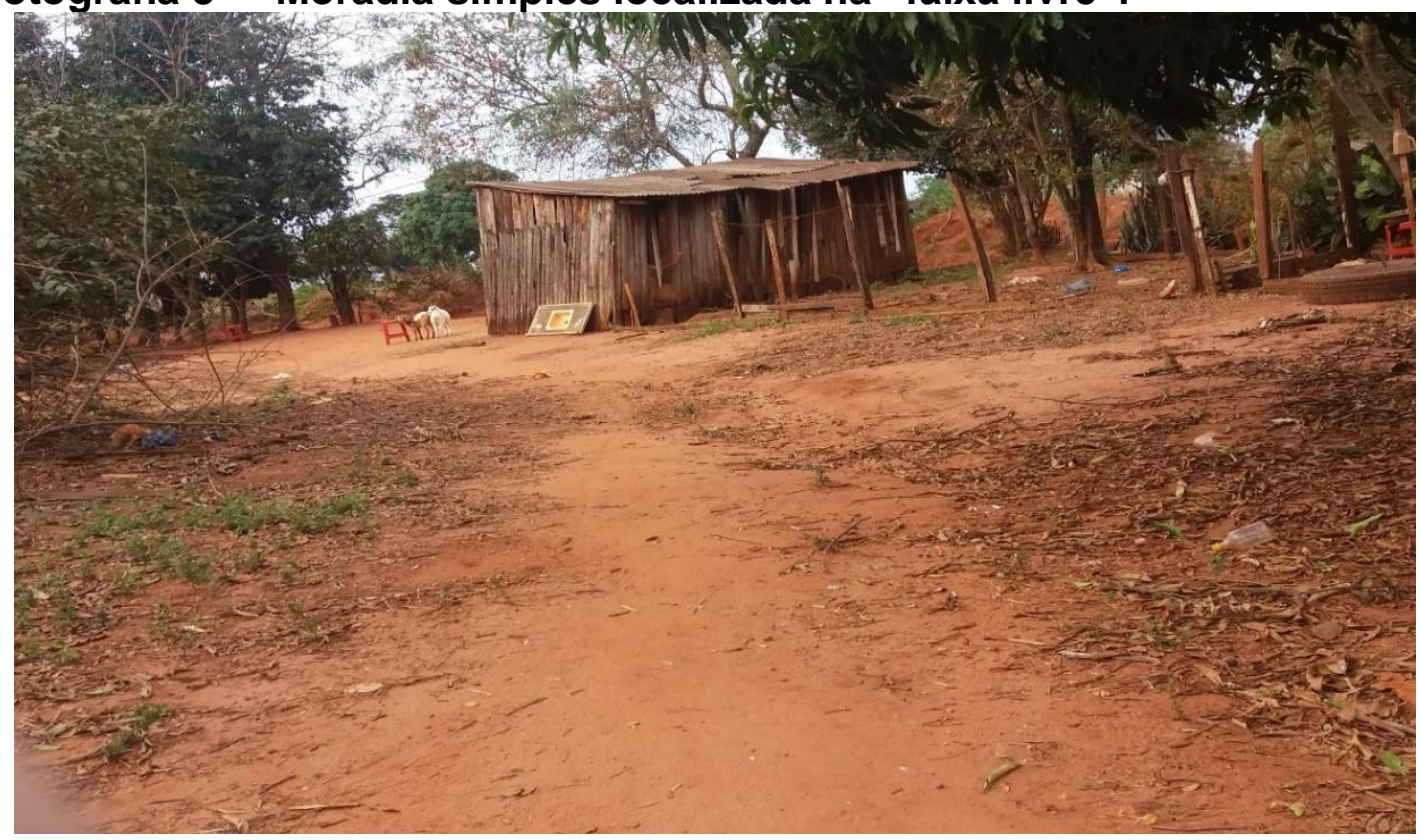

Fonte: SOUZA (2018).

Sobre sua relação com o lugar, Fernando afirma que na região em que reside tem um aspecto de "deserto" e garante estar adaptado com essa

ParaOnde!?, Porto Alegre, v.13, n.2, p.152-164, 2020.http://seer.ufrgs.br/paraonde Edição Especial - VII Seminário Internacional de Estudos Fronteriços 
peculiaridade, "[...] Limpa a casa de manhã e de tarde escreve nos móveis com a poeira", mas ainda assim, Fernando afirma que gosta muito daquele lugar e que não pretende sair de lá.

Ainda em diálogo informal e descontraído, Fernando chama a atenção para o constante contato com o Paraguai, "a população em geral compra muita coisa no Paraguai, mesmo com o dólar alto ainda tá compensando, faz dias que não abasteço no Brasil".

Atilana Gomes, 65 anos, natural de Paranhos-Brasil, é outra entrevistada que viveu boa parte de sua vida em Sete Quedas - Brasil e em Perron Paraguai, atualmente mora próximo à casa de Fernando, também no lado brasileiro, seu sotaque, apesar de ter estudado até a quinta série na escola estadual de ensino básico Treze de Maio (Sete Quedas), entrega sua convivência na cidade pertencente a outro país, com cultura e idioma diferentes, viveres múltiplos e particulares que marcaram sua trajetória de vida. Devido a essas vivências, em um primeiro momento, é difícil saber se Atilana é paraguaia ou brasileira, ou talvez seja os dois, uma brasiguaia.

Hoje aposentada, com dificuldade e ao mesmo tempo delicadeza em sua fala, Atilania, é a evidência de como utilizar a língua como recurso para interação e instrumento para estabelecer relações sociais, dado que, através do conhecimento da linguagem facilita o contato e convivência com o outro.

"[...] não tenho o que reclamar desse lugar, criei muito bem meus filhos, tenho netos e bisnetos. Aqui o bairro é mais pacato comparado com os outros, violência sempre tem na fronteira". (MARUCHI; SOUZA, 2018, B)

Essas particularidades encontradas na região de fronteira ficam ainda mais claras na fala dos representantes da prefeitura local de Sete Quedas em uma entrevista realizada junto aos acadêmicos que realizavam a aula de campo. Nesta entrevista, ficou claro que o Estado muitas vezes encontra dificuldades em lidar com essas particularidades típicas de uma região de fronteira e é notória a falta de conhecimento e presença dos representantes estatais nos locais como a "faixa livre" que necessitam de serviços básicos. Durante a entrevista com os representantes das secretarias de saúde, de agricultura, de desenvolvimento econômico e habitacional, de assistência social e de educação da cidade de Sete Quedas foram relatadas diversas dificuldades encontradas pelos representantes públicos locais para lidarem com a população da faixa livre e da fronteira em geral.

O representante da secretaria da agricultura de Sete Quedas descreve rapidamente o processo histórico de formação distribuição dos loteamentos do município. Segundo ele, no início da década de 1970, o Instituto Nacional de Colonização e Reforma Agrária (INCRA) realocou famílias que moravam em locais alagados pela usina hidrelétrica de Itaipu para o município e alguns lotes foram arrendados por famílias vindas do estado do Paraná, deixando claro que não existem assentamentos vinculados ao INCRA.

Ainda, o representante identifica Sete Quedas como parte da área de floresta com frequência de precipitação considerada satisfatória e, portanto, a agricultura é a grande força econômica, seguia pela pecuária, em que

ParaOnde!?, Porto Alegre, v.13, n.2, p.152-164, 2020.http://seer.ufrgs.br/paraonde Edição Especial - VII Seminário Internacional de Estudos Fronteriços 
pequenos proprietários produzem leite e grandes proprietários produzem gado de corte.

Alguns dos problemas relatados pelos secretários são em relação aos serviços de saúde, segundo o secretário de saúde da cidade, cerca de $15 \%$ do público atendido nos hospitais e postos da cidade de Sete Quedas é de origem paraguaia, e, portanto, esta demanda não está contabilizada na verba que é destinada a cidade, uma vez que não deveriam ser atendidos no Brasil, e isto causa alguns problemas como a falta de equipamentos nos hospitais e de veículos de locomoção como ambulâncias devido à falta de verba. O município possui o apoio do programa "Mais Médicos" com três médicos de nacionalidade cubana que se revezam durante os três turnos (matutino, vespertino e noturno) e o hospital da cidade oferece atendimento de urgência e emergência, sendo que as referências em saúde mais próximas são os municípios de Dourados e Ponta Porã, "[...] Mesmo com apoio de outras secretarias, trabalhar na gestão da saúde sempre é difícil, por ser fronteira, atender além da população do município sobrecarrega" (MARUCHI; SOUZA, 2018 C).

Outro grande problema, desta vez relatado pela secretária de assistência social, é que muitas pessoas que vivem no Brasil e que precisam de assistência não possuem documentação, geralmente essas pessoas são de origem paraguaia, mas moram no Brasil ou são familiares de brasileiros, muitas vezes vivem em condições precárias, e essa falta de documentação gera diversos problemas que dificultam a ação do Estado para dar assistência a essa parte da população.

A secretária de assistência social não nega desconhecimento a respeito da situação dos moradores da faixa de fronteira e outras localidades que vivem em situações difíceis, declara que são oferecidos atendimentos de assistentes sociais e projetos de médio e longo prazo, várias oficinas para famílias como curso de manicure, programa de distribuição de cestas básicas e a administração local do programa Bolsa Família realçando a todo o momento a preocupação com a população infantil, "[...] A criança é prioridade" (MARUCHI; SOUZA, 2018 D). Entretanto, o que foi observado e descrito pelas famílias que habitam a faixa de fronteira e os bairros próximos á ela revelam um abandono do poder público em diversos setores de serviços básicos.

A falta de documentação afeta todas as secretárias que administram os serviços básicos, inclusive a secretaria de educação, segundo sua representante, muitos paraguaios que vivem no Brasil encontram dificuldades para poder ter acesso á educação por não terem documento, porém, segundo ela, alguns conseguem o documento e fazem uma prova de nível nominada "reclassificação", e assim, tem a chance de estudar no Brasil. Até o momento, a secretária não tem informações de brasileiros estudando em escolas do ensino básico no Paraguai, o que é corriqueiro são jovens brasileiros que cursam medicina no país vizinhoiv, comum em vários outros municípios da região.

De acordo com a secretária de educação, a rede municipal de ensino possui uma escola urbana, duas escolas de extensão para ensino infantil, quatro extensões rurais e uma escola indígena, todas com uma quantidade mínima de alunos, visto que, existem escolas estaduais que são a preferência

ParaOnde!?, Porto Alegre, v.13, n.2, p.152-164, 2020.http://seer.ufrgs.br/paraonde Edição Especial - VII Seminário Internacional de Estudos Fronteriços 
de muitos pais e estudantes.

Ainda, a secretária afirma que não há verba para projetos que atendam a demanda vinda do Paraguai nas escolas, o município tem projeto para substituir a disciplina de língua moderna inglesa para língua moderna espanhola, no entanto, não possui nenhum professor habilitado. O único projeto que a rede municipal oferece até o momento é o Programa Educacional de Resistência ás Drogas e á Violência (PROERD), projeto que antes atendia escolas municipais de todo o estado, mas que hoje permanece em municípios de fronteira devido aos registros de tráfico e consumo de drogas, o que acaba atestando que o próprio poder público reforça os estereótipos de fronteira.

Devemos lembrar que as escolas locais também são um ótimo instrumento para entendermos as relações presentes na fronteira. A convivência diária, a troca de conhecimento, experiências e necessidade de adaptação são elementos que as crianças, professores e funcionários vivenciam diariamente, marcando e evidenciando a interculturalidade específica da fronteira, podendo ser identificada na língua, nos costumes, no modo de vestir, de arrumar o cabelo, de ver o mundo e suas experiências que trazem de casa.

O secretário de desenvolvimento econômico e habitacional faz um resgate espaço-temporal da composição de loteamento do município. 0 loteamento Iporã I foi uma das primeiras produções habitacionais do município, posteriormente foi lançada a fase dois com o mesmo nome. Com o programa Lotes Urbanizados já foram entregues 130 casas e 13 unidades ainda serão construídas, a falta de terreno para construção ainda não foi resolvida, "[...] É um bom lugar, mesmo com a fama de perigoso" (MARUCHI; SOUZA, $2018 \mathrm{E}$ ).

Segundo o secretário, houve uma modalidade para inscrição de pessoas para concorrerem à habitação, esta modalidade foi denominada "área de risco", que contemplava famílias brasileiras da faixa de fronteira do município, porém, o secretário relata que uma certa quantidade de famílias que receberam a casa em um loteamento específico voltaram a residir na antiga casa improvisada na faixa, o secretário alegou falta de interesse dos contemplados em possuir uma moradia digna, reforçando a falta de sensibilidade na análise do poder público em relação ao citadino e ainda, reforça a falta de sensibilidade de um ser humano com outro ser humano. Nas palavras de Musculini (2012, p. 29):

Trata-se na realidade de referenciais afetivas as quais desenvolvemos ao longo de nossas vidas a partir da convivência com o lugar e com o outro. Eles são carregados de sensações emotivas principalmente porque nos sentimos seguros e protegidos; ele tanto nos transmite boas lembranças quanto à sensação de lar. (MUSCULINI, 2012, p. 29).

Assim, o lugar de residência das pessoas que sobrevivem na faixa de fronteira representa um conjunto de significados originados a partir na experiência, do cotidiano. É uma realidade de referência afetiva com o lugar e com o outro, desenvolvida ao longo de toda uma trajetória árdua de uma vida. O fato de ter um teto não soluciona os problemas, em muitos casos asseveraos, pois existem famílias que moram em casas improvisadas, mas que

ParaOnde!?, Porto Alegre, v.13, n.2, p.152-164, 2020.http://seer.ufrgs.br/paraonde Edição Especial - VII Seminário Internacional de Estudos Fronteriços 
possuem terreno com tamanho suficiente para criarem os animais e plantar grãos e hortaliças para subsistência e venda, mas que muitas vezes não possuem condições de arcar com despesas como conta de energia e tratamento de esgotov; se estas famílias forem realocadas para uma casa em um bairro distante com terreno suficiente apenas para área de serviço, não assegurando condições suficientes para arcar com despesas extras, cria-se mais uma contradição e vários outros problemas: o direito a casa própria, mas sem o direito a cidadania e o direito a cidade.

Vale destacar a fala do secretário de desenvolvimento econômico e habitacional da prefeitura de Sete Quedas, que afirmou a dificuldade em promover políticas públicas para aquela população, e disse ainda, que para o Estado é como se as famílias que habitam na linha internacional não existissem, "são uma terra de ninguém", uma vez que eles estão morando em um lugar neutro á políticas estatais, mesmo que seja parte em território brasileiro (Fotografia 4). A declaração do secretário torna real a invisibilidade daquelas famílias, o "não morar" os configura a uma condição de não existência.

O conjunto habitacional Iporã (Fotografia 4), mencionado pelo secretário de desenvolvimento econômico e habitacional anteriormente, é localizado a leste do município, é um residencial popular que beneficia famílias consideradas "Faixa 1" com renda mensal de até 1,800 reais do Programa Minha Casa Minha Vida em parceria com a prefeitura de Sete Quedas e financiado pelo Fundo de Arrendamento Residencial (FAR) com casas distribuídas entre Iporã I e II. O Iporã é composto por famílias compostas por várias famílias de brasileiros, mas também durante a entrevista com a população local foram encontradas famílias de paraguaios e indígenas de diferentes etnias.

Fotografia 4 - Residencial Iporã (Sete Quedas - MS)

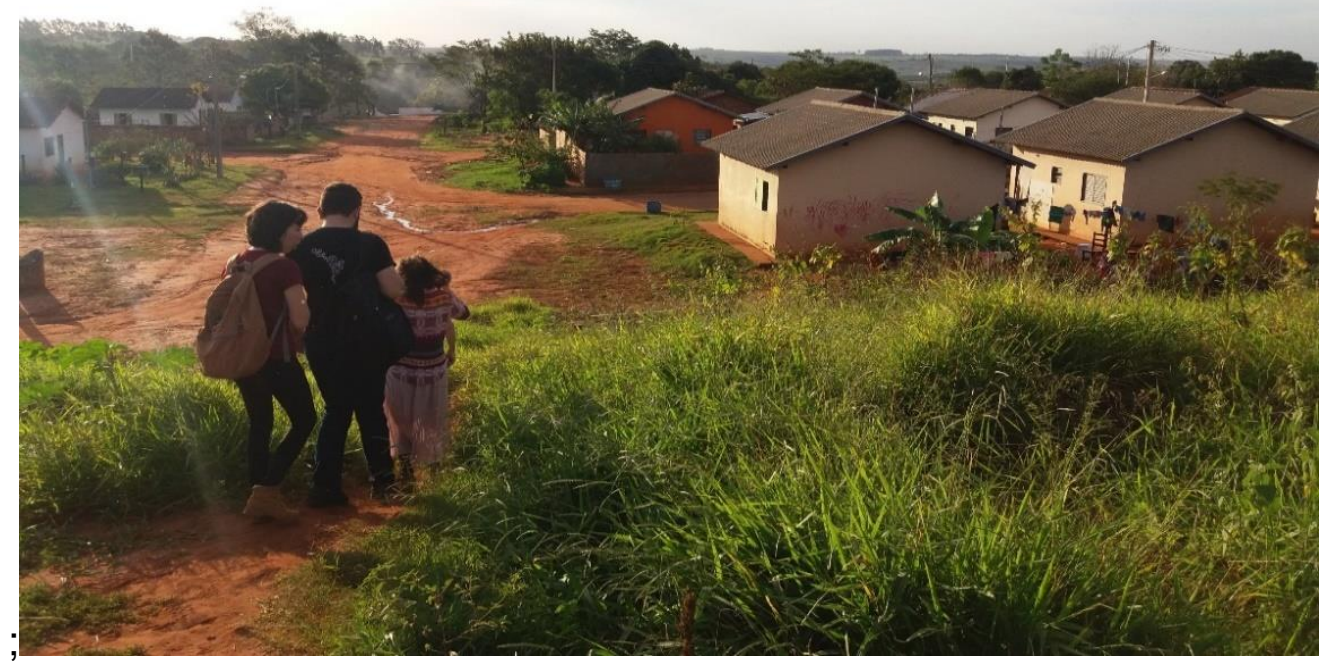

Fonte: MARUCHI, 2018

ParaOnde!?, Porto Alegre, v.13, n.2, p.152-164, 2020.http://seer.ufrgs.br/paraonde Edição Especial - VII Seminário Internacional de Estudos Fronteriços 
Em depoimento de uma moradora do residencial, é possível perceber que mesmo pertencendo à mesma classe econômica de baixo poder aquisitivo dos demais moradores, existe o incomodo de morar no mesmo residencial que paraguaios e indígenas; em sua fala a moradora revela que há furtos e assaltos no bairro por parte dos mesmos, acentuando estereótipos em relação ao outro, é possível identificar na fala da moradora um discurso baseado no preconceito, que é algo enraizado em nossa sociedade á séculos e que se reflete na região de fronteira.

\section{Considerações finais}

Durante o trabalho de campo realizado na região de fronteira no município de Sete Quedas, principalmente na "faixa livre", ficou claro que as famílias que vivem ali se encontram em uma situação muito delicada, ali vivem brasileiros, paraguaios e indígenas de ambas as nacionalidades, o Estado brasileiro e também o paraguaio não dão o suporte necessário para que estes indivíduos tenham acesso a bens e políticas públicas.

A particularidade desse local fica evidenciada nas formas como os moradores que vivem na faixa se adaptam para conseguirem ter um acesso (mesmo que precário) á serviços básicos como energia elétrica, por exemplo. Nas falas de algumas delas foi possível descobrir que alguns não têm água encanada, outros conseguem energia elétrica vinda do Paraguai (que é mais barata que a do Brasil).

Durante a conversa com os representantes da prefeitura local, ficou claro que existem inúmeras dificuldades para o Estado atuar na área de fronteira, entendemos que as particularidades da região de fronteira são um desafio para os governantes locais, mas ainda assim, entende-se que as políticas de assistência para a população da "faixa livre" não estão sendo suficientes, o que coloca aquelas pessoas em uma situação muito delicada.

Apesar dos inúmeros problemas relatados tanto pela população local quanto pelos representantes do Estado, pode-se perceber que a fronteira é um lugar muito rico, onde encontramos diversas identidades/multiplicidades, saberes e vivências únicas que mostram que apesar de suas contradições a fronteira é um lugar muito especial.

\section{Referências}

MASSEY. D. Pelo espaço: uma nova política da espacialidade. Rio de Janeiro: Bertrand Brasil, 2008. 312 p.

MARQUEZ, R. M. Geografias portáteis: arte e conhecimento espacial. 2009. 250 f. Tese (Doutorado em Geografia) - Instituto de Geociências Universidade Federal de Minas Gerais (UFMG). Belo Horizonte, 2009. Disponível em: http://www.geografiaportatil.org/files/geografias-portateis-p.pdf. Acesso em: 09 jan. 2019.

ParaOnde!?, Porto Alegre, v.13, n.2, p.152-164, 2020.http://seer.ufrgs.br/paraonde Edição Especial - VII Seminário Internacional de Estudos Fronteriços 
MARUCHI, L. C.; SOUZA, L. C. L. G. Entrevista concedida no trabalho de campo realizado na cidade de Sete Quedas-MS com o morador Fernando. 2018 A.

. Entrevista concedida no trabalho de campo realizado na cidade de Sete Quedas - MS com a moradora Atilana. 2018 B.

. Entrevista concedida no trabalho de campo realizado na cidade de Sete Quedas - MS pelo Secretário de Saúde do município. 2018 C.

. Entrevista concedida no trabalho de campo realizado na cidade de Sete Quedas - MS pela Secretária de Assistência Social do município. 2018 D.

. Entrevista concedida no trabalho de campo realizado na cidade de Sete Quedas - MS pelo Secretário de Desenvolvimento Econômico do município. $2018 \mathrm{E}$.

MUSCULINI, E. C. A rua como lugar dos viveres e fazeres: transformações e persistências na área central de Dourados MS. 2012. 189 f. Dissertação (Mestrado em Geografia) - Faculdade e Ciências Humanas - Universidade Federal da Grande Dourados (UFGD). Dourados-MS, 2012. Disponível em: http://repositorio.ufgd.edu.br/jspui/bitstream/prefix/193/1/ElaineCristinaMusculini .pdf. Acesso em: 08 jan. 2019.

OLIVEIRA, T. C. M. Para além das linhas coloridas ou pontilhadas: reflexões para uma tipologia das relações fronteiriças. Revista Anpege. V.11, n.15, janjun. 2015, p.233-256. Disponível em: http://ojs.ufgd.edu.br/index.php/anpege/article/view/6454/3400 Acesso em: 15 dez. 2018.

. Uma fronteira nas malhas da rebeldia e da criatividade. Cadernos de Estudos Culturais. V.14, p 32-55, set. 2015. Disponível em: https://periodicos.ufms.br/index.php/cadec/article/view/3353/2637. Acesso em: 15 dez. 2018

RAFFESTIN, C. Por uma geografia do poder. São Paulo: Ática, 1993. 269 p.

RAFFESTIN, C. A ordem e desordem ou os paradoxos da fronteira. In: OLIVEIRA, Tito Carlos Machado (Org.). Território sem limites - Estudos sobre fronteiras. pp. 09-15. Campo Grande: Editora UFMS, 2005. 648p.

\footnotetext{
' As entrevistas realizadas pelos autores no trabalho de campo na cidade de Sete Quedas (MS) entre os dias 12 e 13 de julho de 2018 estão referenciadas neste trabalho como MARUCHI; SOUZA, 2018 A, B, C, D e E.

ii As fotografias apresentadas neste trabalho foram tiradas pelos autores no trabalho de campo na cidade de Sete Quedas (MS) entre os dias 12 e 13 de julho de 2018 e estão referenciadas como MARUCHI (2018) ou SOUZA (2018).

iii Homem, marido, filho, pai de dois meninos, autônomo, fronteiriço.

iv Existem até o momento, 2018, sete universidades de medicina em Pedro Juan Caballero, no Paraguai.

v Algumas famílias relatam que utilizam energia elétrica fornecida pelo Paraguai por ser mais barata, além disso, muitas casas não possuem sistema de esgoto.
}

ParaOnde!?, Porto Alegre, v.13, n.2, p.152-164, 2020.http://seer.ufrgs.br/paraonde Edição Especial - VII Seminário Internacional de Estudos Fronteriços 